\title{
Clinical Study \\ Effect of Bacterial Endotoxins on Superovulated Mouse Embryos In Vivo: Is CSF-1 Involved in Endotoxin-Induced Pregnancy Loss?
}

\author{
Yogesh Kumar Jaiswal, ${ }^{1}$ Madan Mohan Chaturvedi, ${ }^{2}$ and Kaushik Deb ${ }^{1}$ \\ ${ }^{1}$ Molecular Biology and Reproductive Immunology Laboratory, School of Studies in Biochemistry, Jiwaji University, \\ Gwalior, 474 011, India \\ ${ }^{2}$ Department of Zoology, University of Delhi, Delhi, 110 007, India
}

Received 17 May 2006; Accepted 17 August 2006

\begin{abstract}
Mammalian embryonic development is regulated by several cytokines and growth factors from embryonic or maternal origins. Since CSF-1 plays important role in embryonic development and implantation, we investigated its role in gram-negative bacterial LPS-induced implantation failure. The effect of LPS on normal (nonsuperovulated) and superovulated in vivo-produced embryos was assessed by signs of morphological degeneration. A significantly similar number of morphologically degenerated embryos recovered from both nonsuperovulated and superovulated LPS treated animals on day 2.5 of pregnancy onwards were morphologically and developmentally abnormal as compared to their respective controls $(P<.001$. Normal CSF- 1 expression level and pattern were also altered through the preimplantation period in the mouse embryos and uterine horns after LPS treatment. This deviation from the normal pattern and level of CSF-1 expression in the preimplantation embryos and uterine tissues suggest a role for CSF-1 in LPS-induced implantation failure.
\end{abstract}

Copyright (c) 2006 Yogesh Kumar Jaiswal et al. This is an open access article distributed under the Creative Commons Attribution License, which permits unrestricted use, distribution, and reproduction in any medium, provided the original work is properly cited.

\section{INTRODUCTION}

A variety of cell types at the blastocyst implantation site produce growth factors that could play important role(s) in the implantation process. Decidual cells and/or embryos produce transforming growth factor alpha (TGF-alpha), epidermal growth factor (EGF), platelet-derived growth factor (PDGF), fibroblast growth factor (FGF), and colony stimulating factor (CSF-1) (Haimovici et al [1]). Furthermore, receptors for EGF, PDGF, and CSF-1 have been detected on embryonic and trophoblast cells. The receptor for CSF-1 ( $c$ $\mathrm{fms}$ ) has been detected from the early 2-cell stage embryo onwards albeit at low levels. CSF-1 mRNA transcripts have been detected in the oviducts and uterus suggesting a paracrine action of these growth factors during the preimplantation period of embryonic development (Arceci et al [2]).

During pregnancy, a paradoxical relationship exists between the fetal allograft and the maternal immune system. Several studies have demonstrated the adverse and beneficial effects of cytokines and growth factors secreted by activated lymphocytes and monocytes on the development of early embryos, during pathogenic conditions. These evidences have now formed the basis of the "immunotrophism" hypothesis, which suggests that local cytokines and growth factors produced by activated immune cells promote pregnancy. Colony stimulating factor-1 (or CSF-1, also known as macrophage colony stimulating factor, $\mathrm{M}-\mathrm{CSF}$ ) is found in humans as a $90 \mathrm{kd}$ secreted homodimer and a $86 \mathrm{kd}$ membrane-bound form, which is cleaved to release a $46 \mathrm{kd}$ homodimer (Rettenmeir et al [3]). It has been shown that CSF-1 mRNA and its corresponding protein increase 1000 folds in the uterine horns during pregnancy in mouse (Pollard [4]). CSF-1 protein and CSF-1 mRNA expression also increase in the placenta in human with advancing gestation (Kauma et al 1999).

Adequate knowledge on preimplantation embryogenesis is necessary for the successful accomplishment of medically assisted reproductive technology and for embryo biotechnology (Iritani [5]). For carrying out the various embryonic manipulations in vitro, usually, a large number of viable and synchronously developing embryos are required and that can be obtained by superovulation. Silent subclinical gramnegative bacterial infections of the genital tract of pregnant animals may lead to poor quality of collected embryos. We 
designed the present study to evaluate the developmental status of preimplantation embryos developing in vivo in LPStreated pregnant animals under nonsuperovulated/normal and superovulated conditions.

Gram-negative bacterial infections of the genitourinary tract of pregnant women are known to cause abortion, fetal loss, or poor pregnancy outcome (for a review see Deb et al [6]). Gram-negative bacterial endotoxins, lipopolysaccharides (LPS) is the main antigenic component of the gramnegative bacterial cell wall, and is known for its potency to activate the myeloid and nonmyeloid cells to produce cytokines. These cytokines and growth factors exert autocrine and paracrine effects on the surrounding cells and modulate the expression and synthesis of other cytokines. Silent subclinical infections of these bacteria can lead to early pregnancy losses where the mother remains unaware of it (see Deb et al [7]). In a previous study we have established the "minimum dose" of LPS which can compromise blastocyst implantation in mouse (Deb et al [8]). The objectives of this study were to find out if LPS could alter the pattern and level of mRNA expression of CSF-1 in the 2-cell to blastocyst stage embryos and uterine horns at narrow intervals over the preimplantation period of pregnancy in mouse.

\section{MATERIAL AND METHODS}

\section{Superovulation and embryo recovery}

Park strain mice were maintained, superovulated, and mated as described earlier (Deb et al $[9,10])$. Female mice were killed by cervical dislocation on days 1.5, 2.5, 3.5, 4.0, 4.125, $4.25,4.3$, and 4.42 of the preimplantation period of pregnancy. The embryos were recovered on each day of pregnancy by flushing the excised oviducts and uterine horns with sterile PBS in sterile endotoxin free petri-dishes (Deb et al [10]). The recovered embryos were examined under a microscope (Nikon, Japan) and their morphology was studied using 20X and $40 \mathrm{X}$ objectives.

\section{Effect of the "minimum effective dose" of LPS on development of preimplantation stage embryos collected from nonsuperovulated/normal and superovulated pregnant animals}

The "minimum effective dose" of LPS was given through IP route to normal and superovulated pregnant females on day 0.5 of pregnancy. The control animals were treated with equal volume of normal saline. The animals were sacrificed by cervical dislocation on days $1.5,2.5,3.5$, and 4.375 of pregnancy and preimplantation stage embryos were recovered separately by flushing oviducts/uterus collected from control and LPS-treated animals of both the groups with PBS in endotoxin free petri-dishes. The embryos recovered from LPS-treated animals of both the groups during different stages of preimplantation period of pregnancy were counted and examined under a microscope (Nikon, Japan) for visible morphological abnormalities and compared with that of the respective control.

\section{Effect of LPS on expression of CSF-1 in embryos and uterus collected at different stages of preimplantation period of pregnancy}

The experiments were performed to study the effect of LPS on the expression of CSF-1 in embryos and uterus collected at different stages of preimplantation period (ie, days 1.5, 2.5, $3.5,4.0,4.125,4.25,4.33$, and 4.42$)$ of pregnancy by RT-PCR. Park strain mice (6-7 weeks) were superovulated with PMSG and hCG as per the protocol. A "minimum dose" of LPS (ie, $5 \mu \mathrm{g}$ /animal) in $100 \mu \mathrm{L}$ of sterile normal saline (determined in a previous study) was injected to each pregnant animal through IP route on day 0.5 of pregnancy (Deb et al [8]). The control animals received $100 \mu \mathrm{L}$ of sterile normal saline in a similar manner. The animals of both groups were sacrificed at narrow intervals of the preimplantation period (ie, days$1.5,2.5,3.5,4.0,4.125,4.25,4.33$, and 4.42 ) of pregnancy to collect the embryos and uterine horns. A total of about 500 embryos were collected at each time to detect the positive mRNA signals for CSF-1 by RT-PCR.

\section{Extraction of total RNA from uterus and embryos and semiquantitative $R T-P C R$}

Total RNA was extracted from the embryos and uterine horns as described earlier (Deb et al [8]). The reverse transcription polymerase chain reaction (RT-PCR) was carried out using "Titan One tube RT-PCR System" (M/S Boehringer Mannheim, Germany). It was carried out as per the instructions provided by the manufacturer. The upstream and downstream primers for CSF-1 were initially purchased from M/S Clontech, USA, and later synthesized from M/S Genset Singapore Biotech Pte Ltd, Singapore. The primers for $\beta$-actin were synthesized from M/S Genset Singapore Biotech Pte Ltd, Singapore, and were used as internal control throughout the experiments (Weihua et al [11]). The primers used were $5^{\prime}$-CGGGCATCATCCTAGTCTTGCTGACTGTT-3' plus 5' -AAATAGTGGCAGTATGTGGGGGGGCATCCT-3' and 5'-GGGCACAGTGTGGGTGAC-3' plus 5' -CTGGCACCACACCTTCTAAC- $3^{\prime}$ for $\beta$-actin.

\section{Statistical analyses}

Statistical analyses were performed using one-way analysis of variance (ANOVA) with Duncan's multiple range test for comparison of the significance level $(P)$ between control and treated values. A $P<.05$ value was considered as significant difference between the values compared.

\section{RESULTS}

\section{Effect of the "minimum dose" of LPS on development of preimplantation stage embryos collected from nonsuperovulated/normal pregnant animals}

The embryos were recovered from reproductive tracts of control and LPS-treated animals during different stages of preimplantation period (ie, from day 1.5 to 4.375 ) of 
TABLE 1: Effect of the "minimum effective dose" of LPS on development of preimplantation stage embryos collected from nonsuperovulated pregnant animals. Data is expressed as mean $\pm 1 S E M$, with all values given in (\%) of abnormal embryos. Means bearing similar superscripted alphabets do not differ from each other at $P \leq .05$ (based on Duncan's multiple range test). ANOVA: treatment $(\mathrm{T})$, F-value $=304.354$ $(P<.001)$, df 1,16 ; days of pregnancy $(\mathrm{P})$, F-value $=42.761(P<.001)$, df 3,16; $\mathrm{T} \times \mathrm{P}$ interaction F-value $=36.881(P<.001), \mathrm{df} 3,16$.

\begin{tabular}{l|c|cccc|cccc}
\hline & & \multicolumn{4}{|c|}{ Control animals } & \multicolumn{3}{c}{ LPS-treated animals } \\
\cline { 3 - 9 } $\begin{array}{l}\text { Days of } \\
\text { pregnancy }\end{array}$ & $\begin{array}{l}\text { No of } \\
\text { animals } \\
\text { used }\end{array}$ & $\begin{array}{l}\text { Total no of } \\
\text { embryos } \\
\text { recovered }\end{array}$ & $\begin{array}{l}\text { No of } \\
\text { abnormal } \\
\text { embryos } \\
\text { recovered }\end{array}$ & $\begin{array}{l}\text { Loss in } \\
\text { yield (\%) }\end{array}$ & $\begin{array}{l}\text { Abnormal } \\
\text { embryos (\%) }\end{array}$ & $\begin{array}{l}\text { Total no of } \\
\text { embryos } \\
\text { recovered }\end{array}$ & $\begin{array}{l}\text { No of } \\
\text { abnormal } \\
\text { embryos } \\
\text { recovered }\end{array}$ & $\begin{array}{l}\text { Loss in } \\
\text { yield (\%) }\end{array}$ & $\begin{array}{l}\text { Abnormal } \\
\text { embryos (\%) }\end{array}$ \\
\hline 1.5 & 3 & $27 \pm 2$ & $0 \pm 2$ & 0 & $4 \pm 2^{(\mathrm{e})}$ & $27 \pm 2$ & $0 \pm 2$ & 0 & $4 \pm 2.17^{(\mathrm{e})}$ \\
2.5 & 3 & $27 \pm 2$ & $0 \pm 2$ & 0 & $4 \pm 2.18^{(\mathrm{e})}$ & $23 \pm 2$ & $15 \pm 2$ & 15 & $65 \pm 5.022^{(\mathrm{b})}$ \\
3.5 & 3 & $27 \pm 2$ & $2 \pm 1$ & 0 & $7 \pm 2.027^{(\mathrm{c})}$ & $20 \pm 2$ & $15 \pm 3$ & 26 & $75 \pm 8.66^{(\mathrm{b})}$ \\
4.375 & 3 & $27 \pm 2$ & $2 \pm 1$ & 0 & $7 \pm 2.027^{(\mathrm{c})}$ & $6 \pm 3$ & $6 \pm 1$ & 78 & $94 \pm 5.56^{(\mathrm{a})}$ \\
\hline
\end{tabular}

pregnancy to assess the effect of LPS on preimplantation embryonic development.

\section{Day 1.5 of pregnancy}

Developmentally normal 2-cell stage embryos were recovered from oviducts of control and LPS-treated animals on day 1.5 of pregnancy (Figures $1(\mathrm{a}), 1(\mathrm{e})$ ). The average numbers of embryos collected from control and LPS-treated animals were found to be the same. Moreover, equal number of abnormal embryos was recovered from control and LPStreated animals (Table 1).

\section{Day 2.5 of pregnancy}

The embryos recovered from oviducts of control animals on day 2.5 of pregnancy were normal and were at $4-8$ cell stage of development (Figure 1(b)). However, developmentally arrested and apoptotic embryos with fully and/or partially degenerated blastomeres were recovered from oviducts of LPS-treated animals (Figure 1(f)). It was also observed that $4 \pm 2.18 \%$ and $65 \pm 5.022 \%$ of embryos collected from control and LPS-treated animals, respectively, were developmentally abnormal (Table 1). The average number of embryos retrieved from LPS-treated animals also declined by $15 \%$ as compared to that of the control (Table 1). A significant increase in the number of abnormal embryos recovered was observed from LPS-treated animals as compared to that of the control $(P<.05)$.

\section{Day 3.5 of pregnancy}

The embryos were recovered from uterus instead of oviducts of control and LPS-treated animals on day 3.5 of pregnancy. The embryos recovered from control animals were at the morula stage of development. However, asynchronously cleaved and degenerated embryos with clear sign of apoptotic bodies were recovered from LPS-treated animals (Figures $1(\mathrm{c}), 1(\mathrm{~g}))$. It was observed that $7 \pm 2.207 \%$ and $75 \pm 8.66 \%$ of embryos retrieved from control and LPS-treated animals, respectively, were developmentally abnormal (Table 1 ). The number of embryos that was recovered on this day of pregnancy from LPS-treated animals was further reduced to $26 \%$ as compared to that of the control.

A significant increase in number of abnormal embryos recovered was observed from LPS-treated animals as compared to that of the control $(P<.05$, Table 1$)$. However, no significant difference in collected abnormal embryos was found from animals treated with LPS on day 3.5 of pregnancy as compared to that on day 2.5 of pregnancy.

\section{Day 4.375 of pregnancy}

The embryos recovered from control animals on day 4.375 of pregnancy were at blastocyst stage of development with intact zona pellucida (ZP) and only $7 \pm 2.207 \%$ of the collected embryos were developmentally abnormal (Figure $1(\mathrm{~d})$ ). However, $94 \pm 5.56 \%$ of total embryos retrieved from LPStreated animals were degenerated/fragmented and without ZP (Figure 1(h)). The average number of embryos recovered from LPS-treated animals was reduced as compared to that of the control. Therefore, $78 \%$ of embryonic loss was observed in LPS-treated animals as compared to that of the control on this day of pregnancy (Table 1). A significant increase in number of developmentally abnormal embryos recovered was observed from LPS-treated animals as compared to that of the control $(P<.001)$. A significant increase in number of abnormal embryos recovered from LPS-treated animals was observed with increase in length of gestational period as compared to that of the control $(P<.001$, Table 1$)$.

\section{Effect of the "minimum dose" of LPS on development of preimplantation stage superovulated embryos collected from pregnant animals}

The embryos were collected from reproductive tracts of superovulated control and LPS-treated pregnant animals during different stages of preimplantation period (ie, from day 1.5 to 4.375 ) of pregnancy to assess the effect of LPS on preimplantation embryonic development in superovulated pregnant animals. 


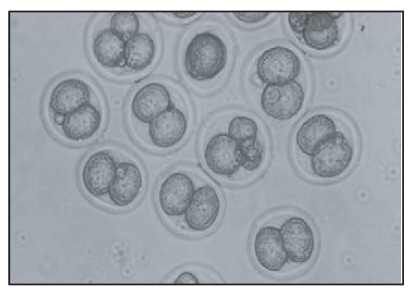

(a)

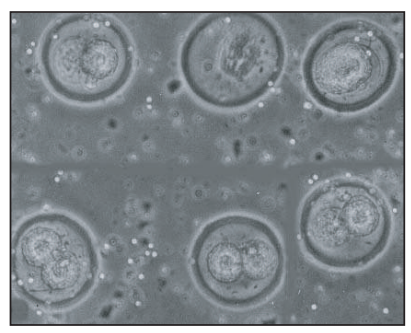

(e)

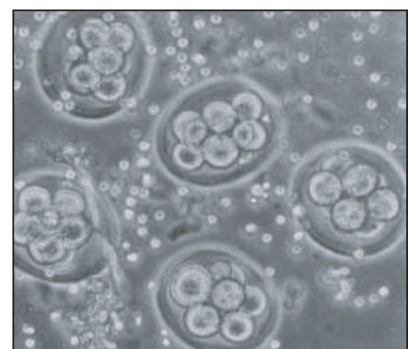

(b)

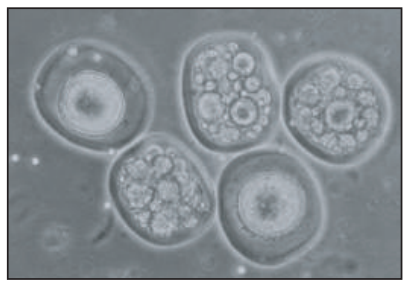

(f)

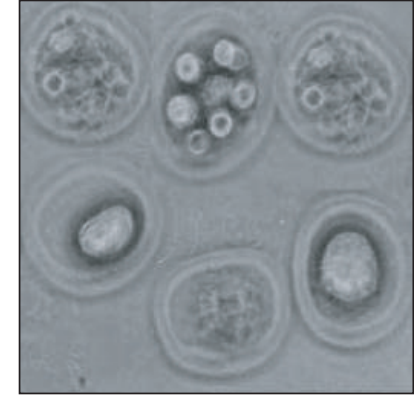

(c)

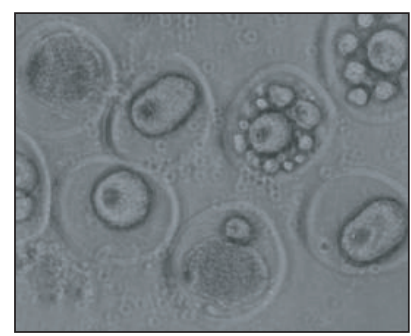

(g)

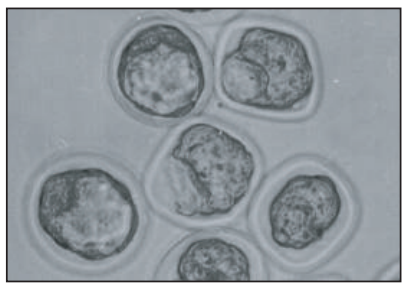

(d)

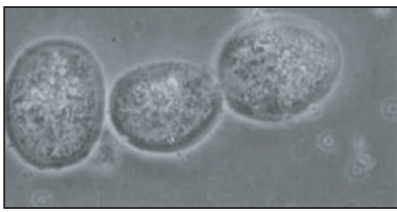

(h)

FIGURE 1: Photograph of embryos recovered from control and LPS-treated nonsuperovulated pregnant mice during different stages of preimplantation period of pregnancy. Panels (a), (b), (c), and (d) show embryos recovered from control animals on days 1.5, 2.5, 3.5, and 4.375 of pregnancy, respectively. Panels (e), (f), (g), and (h) show embryos recovered from the animals treated with the "minimum dose" of LPS on days $1.5,2.5,3.5$, and 4.375 of pregnancy, respectively, X100.

\section{Day 1.5 of pregnancy}

An average of $29 \pm 5$ embryos was harvested from superovulated control and LPS-treated animals on day 1.5 of pregnancy. The recovered superovulated embryos from both groups of animals were normal and were at 2-cell stage of development (Figures 2(a), 2(e)). No significant differences in the quantity of developmentally abnormal embryos were observed in the total embryos recovered from control and LPStreated pregnant animals on this day of pregnancy (Table 2).

\section{Day 2.5 of pregnancy}

The embryos recovered from oviducts of control animals on day 2.5 of pregnancy were normal and were at $4-8$ cell stage of development (Figure 2(b)). However, developmentally arrested and apoptotic embryos with fully or partially degenerated blastomeres were recovered from oviducts of LPS-treated animals (Figure 2(f)). The average yield of superovulated embryos from control and LPS-treated animals was found to be similar on this day of pregnancy as compared to the previous day of pregnancy. However, a significant increase in the number of developmentally abnormal embryos recovered was observed from LPS-treated animals as compared to that of the control $(P<.05$, Figures $2(\mathrm{~b})$, 2(f); Table 2). A significant increase in the number of developmentally abnormal embryos recovered from control and
LPS-treated animals on this day of pregnancy was observed as compared to the embryos recovered from the previous day of pregnancy.

\section{Day 3.5 of pregnancy}

The embryos were recovered from the uterus instead of oviduct of control and LPS-treated animals on day 3.5 of pregnancy. The number of embryos harvested on this day of pregnancy from both groups of animals was similar as compared to the previous days of pregnancy. The normal embryos recovered from control animals were at morula stage of development. However, about half of the total embryos collected from LPS-treated animals were developmentally arrested, degenerated, and fragmented (Figures 2(e), 2(g)). A significant increase in the number of developmentally abnormal embryos recovered was observed from LPS-treated animals as compared to that of the control $(P<.05$, Table 2$)$. However, the number of developmentally abnormal embryos from control and LPS-treated animals on this day of pregnancy did not differ significantly from the previous day of pregnancy.

\section{Day 4.375 of pregnancy}

The embryos recovered from control animals on day 4.375 of pregnancy were at blastocyst stage of development with 


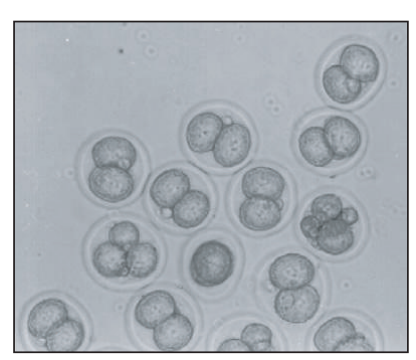

(a)

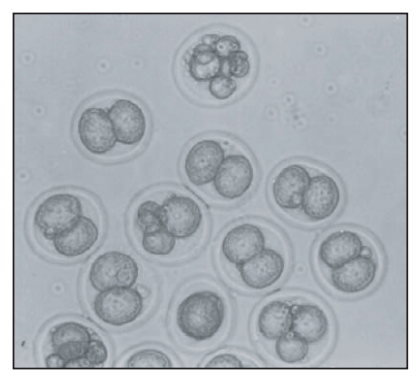

(e)

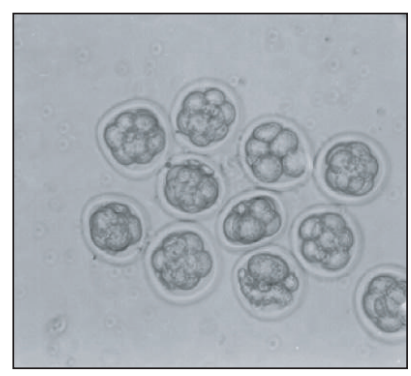

(b)

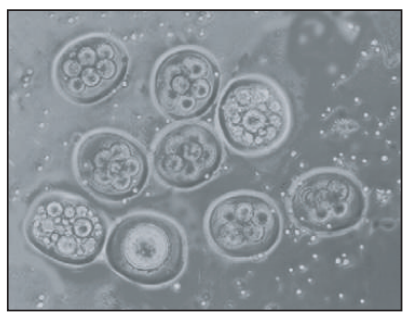

(f)

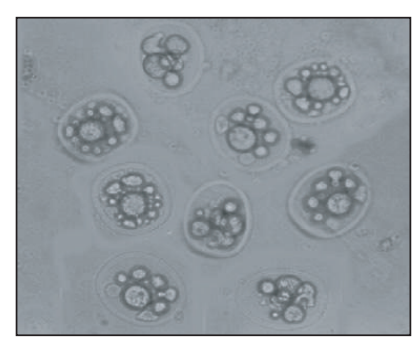

(c)

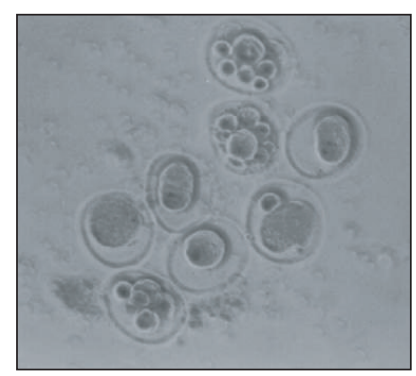

(g)

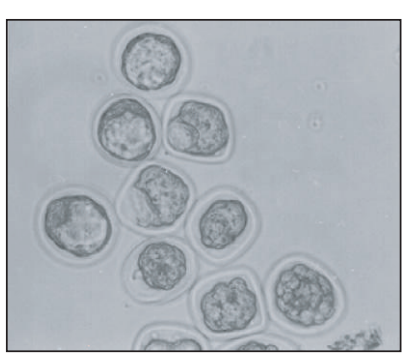

(d)

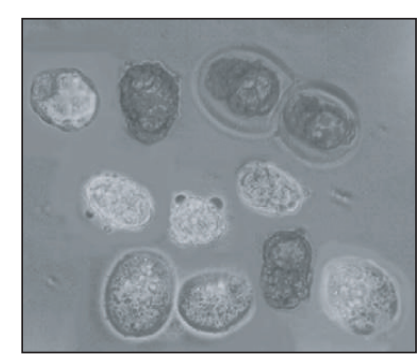

(h)

Figure 2: Photograph of embryos recovered from control and LPS-treated superovulated pregnant mice during different stages of preimplantation period of pregnancy. Panels (a), (b), (c), and (d) show embryos recovered from control animals on days 1.5, 2.5, 3.5, and 4.375 of pregnancy, respectively. Panels (e), (f), (g), and (h) show embryos recovered from the animals treated with the "minimum dose" of LPS on days $1.5,2.5,3.5$, and 4.375 of pregnancy, respectively, X100.

TABLE 2: Effect of the "minimum effective dose" of LPS on development of preimplantation stage embryos collected from superovulated pregnant animals. Data is expressed as mean \pm 1 SEM, with all values given in (\%) of abnormal embryos. Means bearing similar superscripted alphabets do not differ from each other at $P \leq .05$ (based on Duncan's multiple range test). ANOVA: treatment $(\mathrm{T}), \mathrm{F}-\mathrm{value}=959.694$ $(P<.001)$, df 1, 24; days of pregnancy $(\mathrm{P}), \mathrm{F}$-value $=251.514(P<.001)$, df 3,24; $\mathrm{T} \times \mathrm{P}$ interaction F-value $=195.104(P<.001), \mathrm{df} 3,24$.

\begin{tabular}{|c|c|c|c|c|c|c|c|c|c|}
\hline \multirow[b]{2}{*}{$\begin{array}{l}\text { Days of } \\
\text { pregnancy }\end{array}$} & \multirow[b]{2}{*}{$\begin{array}{l}\text { No of } \\
\text { animals } \\
\text { used }\end{array}$} & \multicolumn{4}{|c|}{ Control animals } & \multicolumn{4}{|c|}{ LPS-treated animals } \\
\hline & & $\begin{array}{l}\text { Total no of } \\
\text { embryos } \\
\text { recovered }\end{array}$ & $\begin{array}{l}\text { No of } \\
\text { abnormal } \\
\text { embryos } \\
\text { recovered }\end{array}$ & $\begin{array}{l}\text { Loss in } \\
\text { yield (\%) }\end{array}$ & $\begin{array}{l}\text { Abnormal } \\
\text { embryos (\%) }\end{array}$ & $\begin{array}{l}\text { Total no of } \\
\text { embryos } \\
\text { recovered }\end{array}$ & $\begin{array}{l}\text { No of } \\
\text { abnormal } \\
\text { embryos } \\
\text { recovered }\end{array}$ & $\begin{array}{l}\text { Loss in } \\
\text { yield (\%) }\end{array}$ & $\begin{array}{l}\text { Abnormal } \\
\text { embryos }(\%)\end{array}$ \\
\hline 1.5 & 4 & $116 \pm 5$ & $0 \pm 5$ & 0 & $2 \pm 1.199^{(\mathrm{e})}$ & $116 \pm 5$ & $0 \pm 6$ & 0 & $3 \pm 1.472^{(\mathrm{e})}$ \\
\hline 2.5 & 4 & $116 \pm 5$ & $12 \pm 5$ & 0 & $9 \pm 1.914^{(\mathrm{d})}$ & $116 \pm 5$ & $48 \pm 5$ & 0 & $42 \pm 1.658^{(\mathrm{b})}$ \\
\hline 3.5 & 4 & $116 \pm 5$ & $16 \pm 5$ & 0 & $13 \pm 2.179^{(\mathrm{d})}$ & $116 \pm 5$ & $56 \pm 6$ & 0 & $48 \pm 2.041^{(\mathrm{b})}$ \\
\hline 4.375 & 4 & $104 \pm 5$ & $8 \pm 4$ & 10 & $8 \pm 2.027^{(\mathrm{c})}$ & $72 \pm 5$ & $64 \pm 4$ & 38 & $92 \pm 5.566^{(\mathrm{a})}$ \\
\hline
\end{tabular}

intact zona pellucida $(\mathrm{ZP})$ and only $8 \pm 2.027$ of the collected embryos were developmentally abnormal (Figures $2(\mathrm{~d}), 2(\mathrm{~h}))$. However, the total number of recovered embryos declined by $10 \%$ as compared to that of the earlier days of pregnancy. The embryos recovered from LPS-treated animals were shrunken and without ZP. Moreover, the yield of embryos recovered was decreased by $38 \%$ as compared to that of the earlier days of pregnancy. It was found that $92 \pm 5.566 \%$ of the total embryos recovered from LPS-treated animals were developmentally abnormal as compared to that of the control (Table 2). A significant increase in the number of developmentally abnormal embryos recovered was observed from LPS-treated animals as compared to that of the control $(P<.05$, Table 2$)$. A significant increase in the number of recovered abnormal embryos from LPS-treated animals was observed on this day of pregnancy as compared to the previous day of pregnancy. Moreover, a significant increase in the number of abnormal embryos recovered from 
LPS-treated animals was observed with increase in length of gestation period as compared to that of the control $(P<.001$, Table 2).

\section{Expression of CSF-1 in preimplantation embryos and uterine horns}

An average of $29 \pm 5$ embryos per pregnant animal was collected after superovulation. In the present study, about 500 embryos recovered during different stages of the preimplantation period (ie, days 1.5, 2.5, 3.5, 4.0, 4.125, 4.33, and 4.42) of pregnancy from control and LPS-treated animals were used each time to study the expression of CSF-1/M-CSF by RT-PCR. Positive mRNA signal of CSF-1 was observed in developing embryos collected from control and LPS-treated animals from day 1.5 to day 3.5 of gestation period (ie, from 2 -cell stage to the morula stage) (Figures 3(a), 3(b)). However, an abrupt expression of this gene was again observed in embryos collected from LPS-treated animals on day 4.42 of pregnancy (Figure 3(a)). A uniform expression of $\beta$-actin gene was observed in the embryos collected from control and LPS-treated animals during different developmental stages of preimplantation period of pregnancy (Figure 3(c)).

The uterine horns collected from control and LPS-treated animals during different stages of the preimplantation period of pregnancy (ie, days 1.5, 2.5, 3.5, 4.0, 4.125, 4.33, and 4.42 of pregnancy) were used to study the expression of proinflammatory cytokines and growth factors CSF-1 by RT-PCR. Expression of CSF-1 mRNA increased gradually in uterine horns collected from control animals from day 1.5 of pregnancy till implantation (Figure 4(b)). In uterine horns from LPS-treated animals CSF-1 expression decreased between day 3.5 to 4.125 of pregnancy as compared to that of the control. However, its mRNA expression resumed back to normal levels (equivalent to control) from day 4.25 of pregnancy onwards till implantation (Figures 4(a), 4(b)). A uniform expression of $\beta$-actin gene was obtained in the uterus collected from control and LPS-treated animals during different developmental stages of pregnancy (Figure 4(c)).

\section{DISCUSSION}

It has been shown that the pathophysiology of microbial infection that induced pregnancy loss in mouse is similar to that in human. Therefore, mouse may be used as a reliable and reproducible animal model to elucidate the molecular mechanisms of failure of pregnancy (Dudley et al [12]). To elucidate the mechanism of LPS-induced failure of implantation we investigated its effect on the in vivo development of preimplantation stage embryos collected from nonsuperovulated/normal and superovulated pregnant animals. We observed that the LPS had more or less similar effects on the quality and quantity of embryos collected from the nonsuperovulated and superovulated animals. The abrupt decline in the quality and quantity of the embryos in response to LPS on day 4.375 of pregnancy may be one of the causes of reduced reproductive efficiencies during gram-negative bacterial infections (Rupasri et al [13]).
The observed asynchronous cleavage and degeneration of preimplantation embryos recovered from LPS-treated animals may be due to activation of LPS-triggered apoptotic pathways in the cells of developing preimplantation embryos. Zou et al [14] suggested that LPS triggers F as mediated apoptotic pathway in mouse preimplantation (2-cell stage) embryos. It has also been reported that the expression of genes involved in cell death (eg, MA-3, p53, Bad, and Bcl$\mathrm{xS}$ etc) gets elevated and that of the genes involved in cell survival (eg, Bcl-2) gets downregulated in embryos undergoing fragmentation (Jurisicova et al [15] and Levy [16]). The present study clearly demonstrates that LPS is associated with severe degeneration and fragmentation of mouse embryos in vivo. This may be due to an early expression of several proinflammatory cytokines in response to LPS in the developing mouse embryos.

The early preimplantation stage embryos are maintained in a nonadhesive state by a nonadhesive proteinaceous coat of ZP (Foulk [17]). The ZP prevents the attachment of the prematured embryo to the endometrium and also helps in the transfer of the developing embryos from the oviducts to the uterus (Carson et al [18]). The zona is shed from the surface of the matured blastocyst just before implantation (ie, on day 4.5 of pregnancy) under normal pregnancy and makes it attachment-competent. However, we saw an early loss of zona pellucida (on day 4.37 of pregnancy) from the developing embryos in response to LPS. The early loss of ZP may expose the premature blastocyst to high levels of cytotoxic factors, which may lead to the fragmentation and degeneration of developing embryos in mouse.

This study clearly implies that the low dose of LPS used in the present experiment may mimic the pathophysiology of subclinical genital tract infection of gram-negative bacteria, which may not affect the uterine preparation for embryonic receptivity at the gross anatomical or physiological levels. Our study also indicates that the preimplantation embryonic development is susceptible to low level of LPS in vivo. The present observations clearly demonstrate that LPS significantly affects the morphology and development of the superovulated embryos, which suggests the mouse embryos produced in vivo may be a good model to study such complications. It is possible that the growth factors and cytokines of embryonic and/or maternal origin, which are produced in response to LPS may alter the molecular dialogue at the feto-maternal interface, which may lead to poor pregnancy outcome and infertility in mouse.

CSF-1 performs several functions during implantation and placentation in physiological pregnancy. Bhatnagar et al [19], in an in vitro study, have shown that CSF-1 stimulates the development of trophectoderm of the blastocyst. CSF-1 regulates growth, differentiation, and functions of macrophages, is readily detectable in the peripheral blood in the steady state, and is further induced in vivo after infection (Cheers and Stanley [20]) or challenge with LPS (Roth et al [21]). Furthermore, CSF-1 treatment in vivo increased levels of LPS-induced TNF- $\alpha$ and IL-6 (Chapoval et al [22]).

We observed an early expression of CSF-1 gene in the embryos collected from the control animals. Our observation 


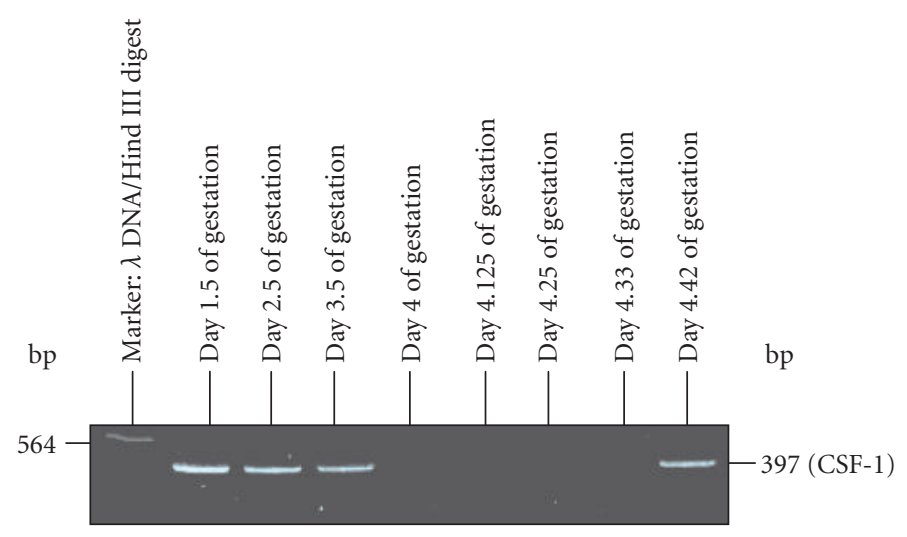

(a)

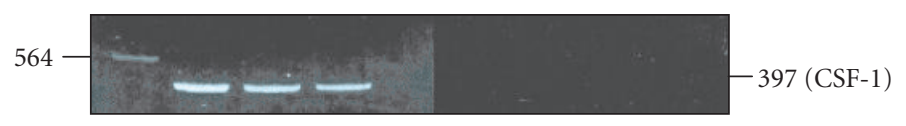

(b)

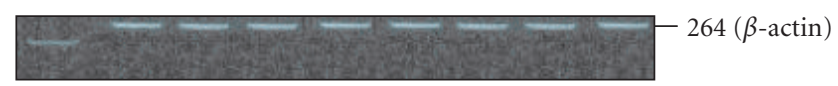

(c)

FIGURE 3: Detection of CSF-1 mRNA transcripts in the preimplantation mouse embryos collected from (a) LPS-treated animals and (b) control animals at the different stages of preimplantation period of pregnancy by RT-PCR. Pannel (c) shows a representative picture showing uniform expression of $\beta$-actin used as an internal control.

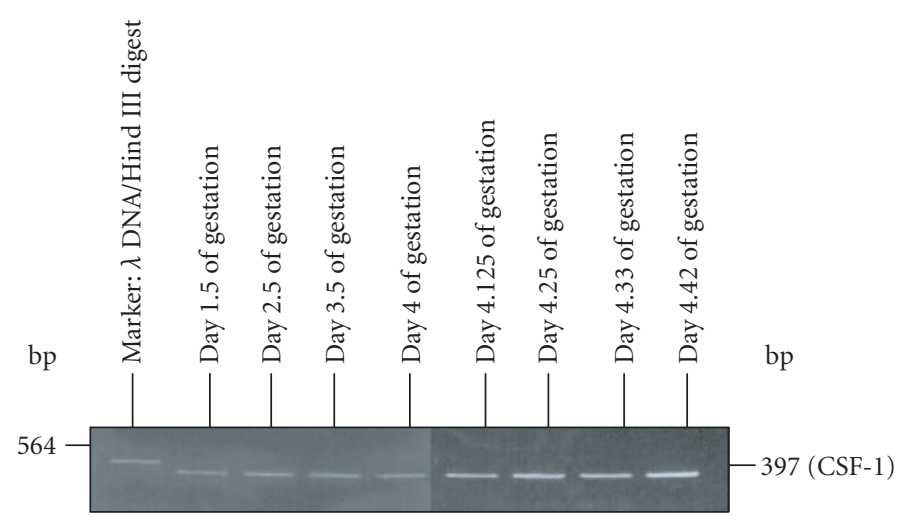

(a)

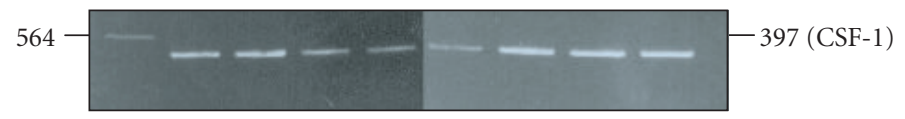

(b)

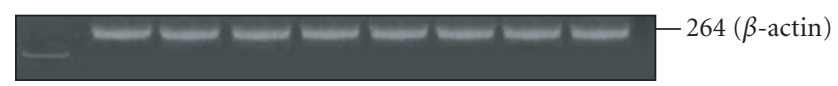

(c)

FIGURE 4: Detection of CSF-1 mRNA transcripts in the mouse uterine horns collected from (a) LPS-treated animals and (b) control animals at the different stages of preimplantation period of pregnancy by RT-PCR. Pannel (c) shows a representative picture showing uniform expression of $\beta$-actin used as an internal control. 
suggests its importance in the normal development of embryos during the early preimplantation stages. Zolti et al [23] reported the expression of CSF-1 in unfertilized human oocytes and during early embryogenesis. However, Arceci et al [2] could not detect its expression in preimplantation embryos in mouse. The pattern of CSF-1 expression in the embryos recovered from LPS-treated animals was similar to that of the control during days 1.5 to 3.5 of pregnancy. However, its abrupt expression in blastocysts (day 4.33) in response to LPS may lead to formation of developmentally compromised blastocysts which are incompetent for implantation.

The increase in CSF-1 production after ovulation and during pregnancy by uterine tissues as observed by us and previous researchers (Pollard et al [4]) may be due to increasing levels of progesterone, which is known to stimulate in vitro production of M-CSF in endometrium (Azuma et al [24]). The decreased level of CSF-1 mRNA in the uterus of animals treated with LPS as compared to that of the control animals on days 3.5, 4.0, and 4.125 of pregnancy indicates that LPS may have a slight antiprogestrogenic activity. The observed decrease in the expression of CSF-1, in the present study, in response to the treatment of animals with LPS may decrease uterine receptivity to the implanting blastocyst and may lead to unsuccessful implantation.

The ability of LPS to induce a differential regulation of the expression of CSF-1 in uterine horns and the preimplantation embryos suggests the possibility that the expressions of other cytokines like TNF and IL- 6 were altered by CSF-1. Though the data is semiquantitative in nature, to our knowledge this is the first report which shows a differential expression of CSF- 1 in the uterine horns and preimplantation embryos in response to LPS, and it highlights the importance of a regulated expression of CSF-1 for sustenance of normal pregnancy.

\section{ACKNOWLEDGMENTS}

We are thankful to the All India Council for Technical Education (AICTE), New Delhi, India; and to the Rockefeller Foundation, USA, for grants to the first author. The third author was a recipient of Senior Research Fellowship from the Council for Scientific and Industrial Research (CSIR), New Delhi, India.

\section{REFERENCES}

[1] Haimovici F, Hill JA, Anderson DJ. The effects of soluble products of activated lymphocytes and macrophages on blastocyst implantation events in vitro. Biology of Reproduction. 1991;44(1):69-75.

[2] Arceci RJ, Pampfer S, Pollard JW. Expression of CSF-1/c-fms and SF/c-kit mRNA during preimplantation mouse development. Developmental Biology. 1992;151(1):1-8.

[3] Rettenmier CW, Roussel MF, Ashmun RA, Ralph P, Price K, Sherr CJ. Synthesis of membrane-bound colony-stimulating factor 1 (CSF-1) and downmodulation of CSF-1 receptors in $\mathrm{NIH} 3 \mathrm{~T} 3$ cells transformed by cotransfection of the human CSF-1 and $c$-fms (CSF-1 receptor) genes. Molecular and Cellular Biology. 1987;7(7):2378-2387.
[4] Pollard JW. Role of colony-stimulating factor-1 in reproduction and development. Molecular Reproduction and Development. 1997;46(1):54-61.

[5] Iritani A. Current status of biotechnological studies in mammalian reproduction. Fertility and Sterility. 1988;50(4):543551.

[6] Deb K, Chaturvedi MM, Jaiswal YK. Comprehending the role of LPS in Gram-negative bacterial vaginosis: ogling into the causes of unfulfilled child-wish. Archives of Gynecology and Obstetrics. 2004;270(3):133-146.

[7] Deb K, Chaturvedi MM, Jaiswal YK. Gram-negative bacterial endotoxin-induced infertility: a birds eye view. Gynecologic and Obstetric Investigation. 2004;57(4):224-232.

[8] Deb K, Chaturvedi MM, Jaiswal YK. A 'minimum dose' of lipopolysaccharide required for implantation failure: assessment of its effect on the maternal reproductive organs and interleukin- $1 \alpha$ expression in the mouse. Reproduction. 2004;128(1):87-97.

[9] Deb K, Chaturvedi MM, Jaiswal YK. Gram-negative bacterial LPS induced poor uterine receptivity and implantation failure in mouse: alterations in IL- $1 \beta$ expression in the preimplantation embryo and uterine horns. Infectious Diseases in Obstetrics and Gynecology. 2005;13(3):125-133.

[10] Deb K, Reese J, Paria BC. Methodologies to study implantation in mice. In: Soares MJ, Hunt JS, eds. Placenta and Trophoblast: Methods and Protocols. Vol. 1. Chapter 1. Totowa, NJ: Humana Press; 2005:9-34.

[11] Weihua Z, Saji S, Mäkinen S, et al. Estrogen receptor (ER) $\beta$, a modulator of ER $\alpha$ in the uterus. Proceedings of the $\mathrm{Na}$ tional Academy of Sciences of the United States of America. 2000;97(11):5936-5941.

[12] Dudley DJ, Chen C-L, Branch DW, Hammond E, Mitchell MD. A murine model of preterm labor: inflammatory mediators regulate the production of prostaglandin $E_{2}$ and interleukin-6 by murine decidua. Biology of Reproduction. 1993;48(1):33-39.

[13] Rupasri A, Shivakumar KR, Sreenath BR, Seshagiri PB. Assessment of developmental retardation and abnormality of in vivo produced preimplantation embryos in rat. Indian Journal of Experimental Biology. 1995;33(12):911-916.

[14] Zou G-M, Reznikoff-Etiévant M-F, Léon A, Vergé V, Hirsch F, Milliez J. Fas-mediated apoptosis of mouse embryo stem cells: its role during embryonic development. American Journal of Reproductive Immunology. 2000;43(4):240-248.

[15] Jurisicova A, Latham KE, Casper RF, Varmuza SL. Expression and regulation of genes associated with cell death during murine preimplantation embryo development. Molecular Reproduction and Development. 1998;51(3):243-253.

[16] Levy R. Genetic regulation of preimplantation embryo survival. International Review of Cytology. 2001;210:1-37.

[17] Foulk RA. From fertilization to implantation. Early Pregnancy. 2001;5(1):61-62.

[18] Carson DD, Bagchi I, Dey SK, et al. Embryo implantation. Developmental Biology. 2000;223(2):217-237.

[19] Bhatnagar P, Papaioannou VE, Biggers JD. CSF-1 and mouse preimplantation development in vitro. Development. 1995; 121(5):1333-1339.

[20] Cheers C, Stanley ER. Macrophage production during murine listeriosis: colony-stimulating factor 1 (CSF-1) and CSF-1binding cells in genetically resistant and susceptible mice. Infection and Immunity. 1988;56(11):2972-2978.

[21] Roth P, Bartocci A, Stanley ER. Lipopolysaccharide induces synthesis of mouse colony-stimulating factor-1 in vivo. Journal of Immunology. 1997;158(8):3874-3880. 
[22] Chapoval AI, Kamdar SJ, Kremlev SG, Evans R. CSF-1 (MCSF) differentially sensitizes mononuclear phagocyte subpopulations to endotoxin in vivo: a potential pathway that regulates the severity of Gram-negative infections. Journal of Leukocyte Biology. 1998;63(2):245-252.

[23] Zolti M, Ben-Rafael Z, Meirom R, et al. Cytokine involvement in oocytes and early embryos. Fertility and Sterility. 1991;56(2):265-272.

[24] Azuma C, Saji F, Kimura T, et al. Steroid hormones induce macrophage colony-stimulating factor (MCSF) and MCSF receptor mRNAs in the human endometrium. Journal of Molecular Endocrinology. 1990;5(2):103-108. 


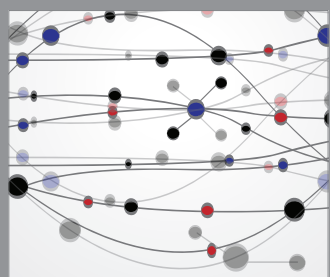

The Scientific World Journal
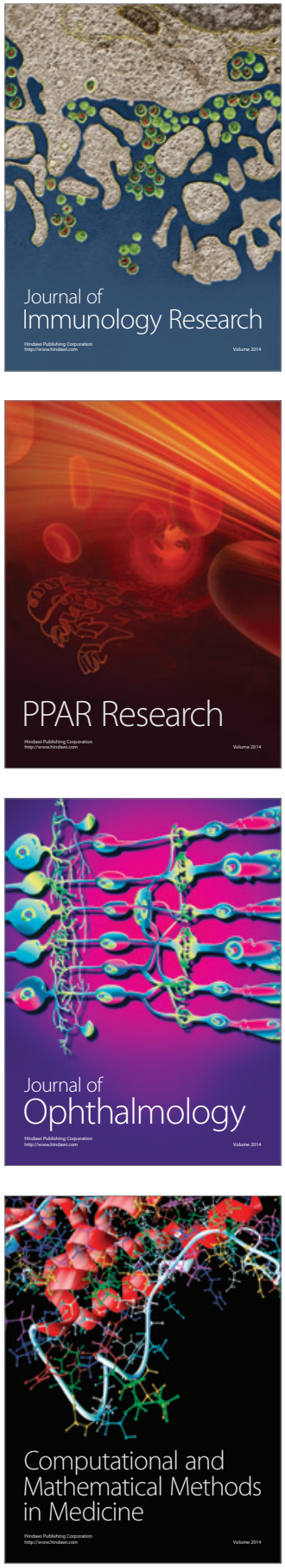

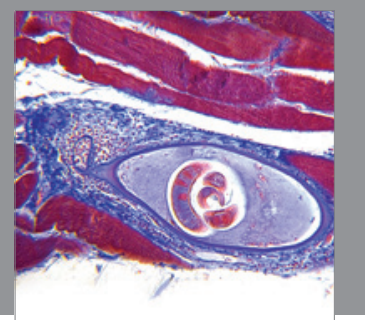

Gastroenterology

Research and Practice
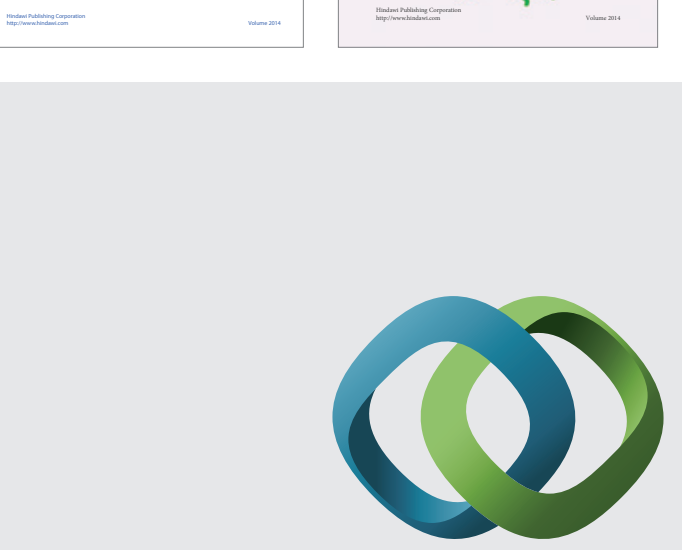

\section{Hindawi}

Submit your manuscripts at

http://www.hindawi.com
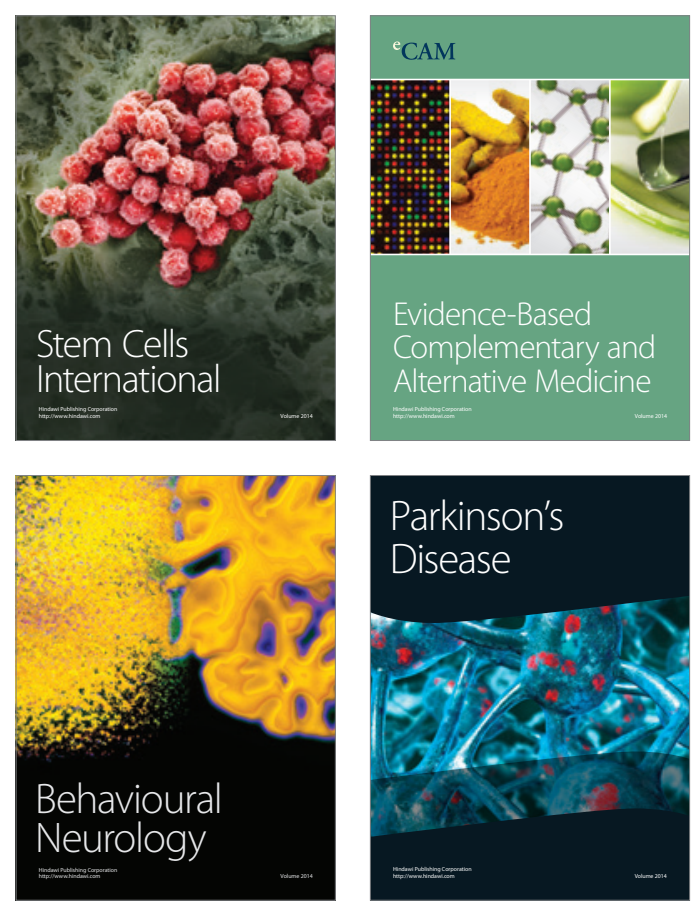

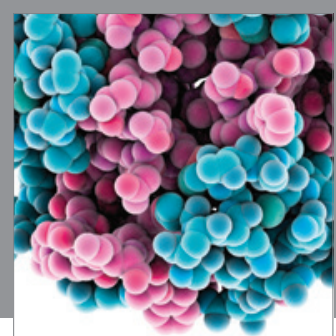

Journal of
Diabetes Research

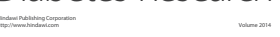

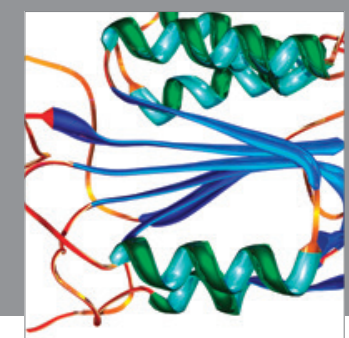

Disease Markers
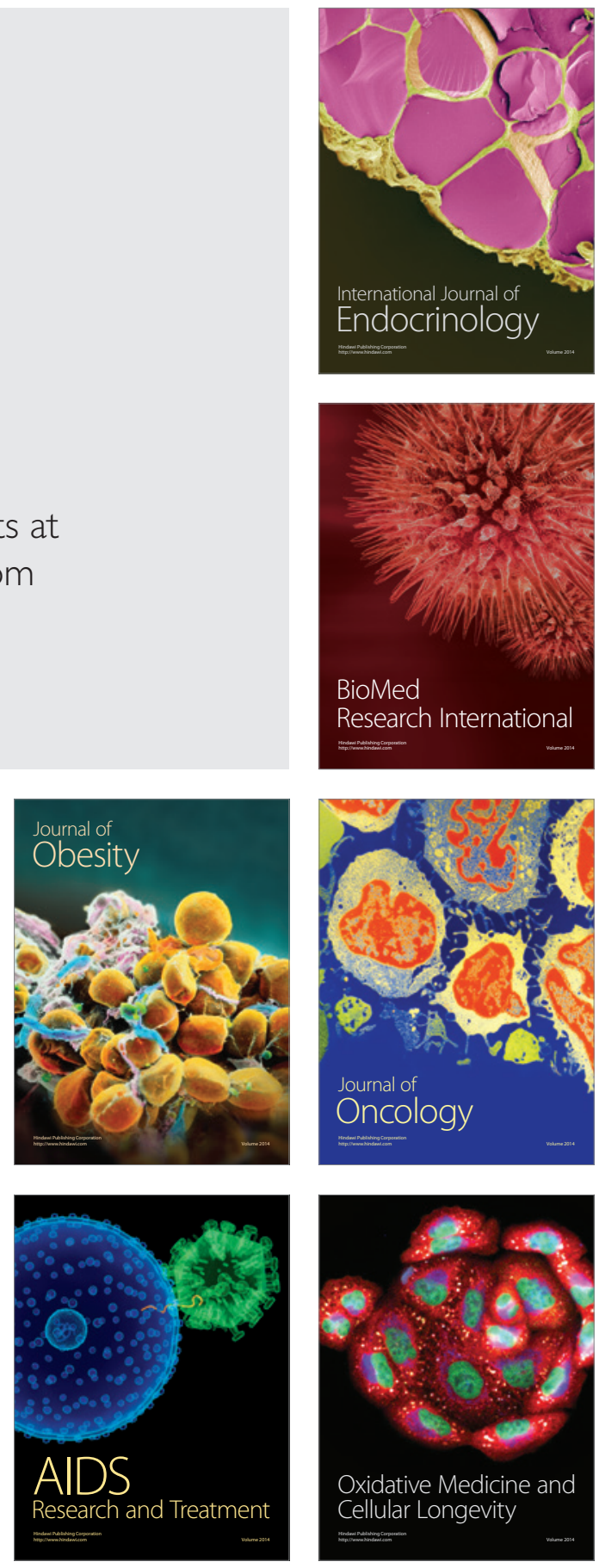